\title{
Angiopoietin/Tie2 Signaling Transforms Capillaries into Venules Primed for Leukocyte Trafficking in Airway Inflammation
}

\author{
Jonas Fuxe, ${ }^{*}$ Erin Lashnits, ${ }^{*}$ Shaun O'Brien, ${ }^{*}$ \\ Peter Baluk, ${ }^{*}$ Sebastien P. Tabruyn, ${ }^{*}$ \\ Frank Kuhnert, ${ }^{\dagger}$ Calvin Kuo, ${ }^{\dagger}$ Gavin Thurston, ${ }^{\ddagger}$ \\ and Donald M. McDonald*

\begin{abstract}
From the Cardiovascular Research Institute, Comprehensive Cancer Center, and Department of Anatomy, University of California San Francisco, San Francisco, California; the Department of Medicine, Hematology Division, ${ }^{\dagger}$ Stanford University School of Medicine, Stanford, California; and
\end{abstract} \\ Regeneron Pharmaceuticals, ${ }^{\ddagger}$ Tarrytown, New York
}

Vascular endothelial growth factor (VEGF) is a key angiogenic factor in tumors, but less is known about what drives vascular remodeling in inflammation, where plasma leakage and leukocyte influx are prominent features. In chronic airway inflammation in mice infected by the bacterium Mycoplasma pulmonis (M. pulmonis), the segment of the microvasculature that supports leukocyte adhesion and migration expands through remodeling of capillaries into vessels with features of venules. Here, we report that the angiopoietin/Tie2 pathway is an essential driving force for capillary remodeling into venules in $\mathrm{M}$. pulmonisinfected mouse airways. Similar to M. pulmonis infection, systemic overexpression of angiopoietin-1 (Ang1) resulted in remodeling of airway capillaries into venular-like vessels that expressed venous markers like $\mathbf{P}$ selectin, ICAM-1, and EphB4 and were sites of leukocyte adhesion during lipopolysaccharide-induced acute inflammation. Ang1 and Ang2 protein increased in $M$. pulmonis-infected mouse airways but came from different cellular sources: Ang1 was expressed in infiltrating neutrophils and Ang2 in endothelial cells. Indeed, systemic administration of soluble Tie 2 inhibited capillary remodeling, induction of venous markers, and leukocyte influx in M. pulmonis-infected mouse airways. Together, these findings suggest that blockade of the Ang/ Tie2 pathway may represent a therapeutic approach in airway inflammation. (Am J Pathol 2010, 176:2009-2018; DOI: 10.2353/ajpath.2010.090976)
Angiogenesis and vascular remodeling are important features of tumors and inflammatory conditions. Inhibition of blood vessel growth by blocking sprouting angiogenesis is becoming an important component of cancer therapy, ${ }^{1,2}$ but targeting the growth and remodeling of blood vessels in inflammatory disease is less advanced. ${ }^{3}$ In acute inflammation, plasma leakage and leukocyte migration are restricted to venules, but in chronic inflammation the responsive region of the microvasculature expands by transformation of capillaries into a venular phenotype. ${ }^{4,5}$ Although the remodeled vessels have been considered enlarged, dilated, or engorged capillaries because of their location and size, they have features of venules and thereby contribute to the gatekeeper role of venules in controlling plasma extravasation and leukocyte infiltration. ${ }^{5}$ Such remodeled vessels are seen in the airways of asthmatics, ${ }^{6}$ skin lesion of psoriasis, ${ }^{7}$ and intestine of inflammatory bowel disease. ${ }^{8}$ The ubiquitous presence of abnormal blood vessels that are responsible for plasma leakage, leukocyte infiltration, and other features of chronic inflammation make the remodeled vasculature a potential therapeutic target. ${ }^{9}$

Angiogenesis in tumors is driven by VEGF and other growth factors, ${ }^{1,2}$ but less is known about the molecules

Supported by NIH grants HL-24136 and HL-59157 (to D.M.M.) and HL74267 and CA-95654 (to C.J.K.). J.F. was supported by the Swedish Wenner-Gren Foundation, the Swedish Research Council, the Swedish Childhood Cancer Foundation, and by a UICC American Cancer Society International Fellowship for Beginning Investigators. F.K. was supported by a postdoctoral Fellowship from American Heart Association. S.P.T. was supported by a fellowship of the Belgian American Educational Foundation and a fellowship of the "Centre Anticancéreux" (University of Liege, Belgium).

Accepted for publication December 7, 2009.

Supplemental material for this article can be found on http://ajp. amjpathol.org.

Current address for J.F.: Department of Medical Biochemistry and Biophysics (MBB), Matrix Division, Karolinska Institute, Stockholm, Sweden.

Address reprint requests to Donald M. McDonald, M.D., Ph.D., Department of Anatomy, University of California San Francisco, 513 Parnassus Avenue, S1363, San Francisco, CA 94143-0452. E-mail: donald.mcdonald@ ucsf.edu. 
involved in vascular remodeling in inflammation. VEGF is not a driving force for capillary remodeling in inflammation. ${ }^{3}$ On the contrary, recent data suggest that VEGF has a role in maintaining the endothelium in a nonactivated state. ${ }^{10}$ Angiopoietins are candidates because they are increased in inflammation and they induce vascular remodeling through distinctive actions on endothelial cells, including circumferential vessel enlargement without angiogenic sprouting. ${ }^{11,12}$ The angiopoietin family consists of three members (Ang1, 2, 3 in mice; Ang1, 2, 4 in humans). ${ }^{13}$ All are secreted ligands for Tie2 receptors with potential roles in inflammation. ${ }^{9,14}$ Ang 1 and Tie2 are essential for vascular remodeling during development, ${ }^{15,16}$ whereas Ang2-null mice are viable at birth but have lymphatic defects. ${ }^{17}$ Ang1 induces rapid Tie2 receptor phosphorylation, and its effects in endothelial cells are dependent on cell confluence and tethering of the Tie2 receptor at cell-cell or cell-matrix contacts. ${ }^{18,19}$ Ang2 and Ang3 were initially reported to be incapable of inducing phosphorylation of Tie2 and therefore considered as Tie2 antagonists. ${ }^{14,20}$ However, recent data show that Ang2, like Ang1, can activate Tie2 signaling, suggesting that the effects of Ang2 are context-dependent. $^{21,22}$ Systemic overexpression of Ang1, Ang2, or Ang3 in adult mice causes enlargement of capillaries in the mouse airways due to endothelial cell proliferation. ${ }^{11,12,23}$ The remodeling resembles the enlargement of tracheal capillaries, which occurs during airway infection with the bacterium Mycoplasma pulmonis (M. pulmonis). ${ }^{3}$ Similar to remodeled capillaries in $M$. pulmonisinfected mouse airways Ang1-remodeled capillaries express P-selectin and von Willebrand factor typical of venous endothelial cells. ${ }^{12,24}$

Based on the capacity of the Ang/Tie2 pathway to mediate vascular remodeling in development and in adult tissues, we hypothesized that this pathway could mediate vascular remodeling also in inflammation. We specifically asked whether Ang/Tie2 signaling promotes the remodeling of capillaries into venules, which is typical of sustained/chronic inflammation. To test this we used the vasculature of the mouse trachea as a model system because of its simple architecture, accessibility to reagents via the bloodstream or airway lumen, and distinctive vascular remodeling after infection by $M$. pulmonis. ${ }^{3}$ Adenoviral vectors expressing Ang1 or soluble Tie2 (sTie2) were used in gain- or loss-of-function experiments to evaluate the role of the Ang/Tie2 pathway in vascular remodeling after $M$. pulmonis infection.

\section{Materials and Methods}

\section{Mice}

Pathogen-free C57BL/6 mice (Charles River, Hollister, CA) were housed under barrier conditions. The Institutional Animal Care and Use Committees (IACUC) of the University of California at San Francisco approved all experimental procedures.

\section{Adenoviral Vectors}

Mice were anesthetized with ketamine $(100 \mathrm{mg} / \mathrm{kg})$ and xylazine $(10 \mathrm{mg} / \mathrm{kg})$, and recombinant adenovirus vectors expressing Ang1 (Ad-Ang1), ${ }^{25}$ soluble Tie2 (AdsTie2), ${ }^{26}$ or the $\mathrm{FC}_{\mathrm{C}}$ domain of mouse IgG $\left(\mathrm{Ad}-\mathrm{FC}_{\mathrm{C}}{ }^{26}\right.$ were injected into the left external jugular vein at a dose of $10^{9}$ plaque-forming units. Adenovirus-treated mice were studied 7 days after injection, except when the virus preceded $M$. pulmonis infection by 1 day and the mice were studied 8 days after injection. Based on our previous studies serum concentrations of Ang1, 3 days after the injection of Ad-Ang1 were between 1 and 10 $\mu \mathrm{g} / \mathrm{ml} .{ }^{25,27}$

\section{Induction of Airway Inflammation}

Acute airway inflammation was induced by intranasal inoculation of $250 \mu \mathrm{g}$ of lipopolysaccharide (LPS type 055:B5, Sigma, St. Louis, MO) in $50 \mu$ l saline into anesthetized mice. Mice were studied 2 to 4 hours after inoculation. Sustained airway inflammation was induced by intranasal inoculation of $50 \mu \mathrm{l}$ of broth containing $10^{6}$ colony forming units (CFU) of $M$. pulmonis organisms (strain CT8) into anesthetized mice. ${ }^{28}$ Mice were studied 7 days later.

\section{Immunohistochemistry}

Mice were anesthetized and perfused through the left ventricle with $1 \%$ paraformaldehyde in PBS, pH 7.4. Tracheas were removed and stained as whole-mounts using the following primary antibodies: Platelet endothelial cell adhesion molecule PECAM-1 (clone 2H8, Chemicon, Billerica, MA or clone MEC 13.3, Pharmingen, San Diego, CA); E-selectin (clone 10E9.6; PharMingen); P-selectin (PharMingen); ICAM-1 (clone YN1/1.7.4; eBioscience; San Diego, CA); EphB4 (R\&D Systems, Inc., Minneapolis, MN); Ang1 (ANG11-A, $\alpha$ Diagnostic International Inc., San Antonio, TX); sc-6319 (Santa Cruz Biotechnologies, Santa Cruz, CA); RDI-ANGIOP1XabR (Research Diagnostics, Concord, MA); Ang2 (LS-B58, LifeSpan Biosciences); CD11b (clone M1/70; eBioscience); and CD45 (clone Ly-5; BD Biosciences; San Jose, CA). Secondary antibodies were conjugated to FITC, Cy3, or Cy5 (Jackson ImmunoResearch, West Grove, PA).

Smears of peripheral blood, collected from the tail vein of mice infected with $M$. pulmonis for 7 days, were made on glass slides and stained by immunohistochemistry with antibodies against Ang1, Ang2, CD11b, and CD45, and corresponding secondary antibodies.

Specimens were examined and digital images acquired with a Zeiss Axiophot fluorescence microscope equipped with a CCD camera (CoolCam, SciMeasure Analytical Systems, Atlanta, GA) or a Zeiss LSM-510 confocal microscope.

\section{Measurement of Vascular Remodeling}

Average diameter of tracheal capillaries was measured at the rostro-caudal midpoint of cartilage rings, which 
represented halfway between the venule and arteriole. ${ }^{12}$ Three to five vessels were measured over each of 10 cartilage rings in each trachea.

\section{Measurement of Leukocyte Influx}

Digital fluorescence microscopic images were acquired of regions of tracheal mucosa measuring $960 \times 1280 \mu \mathrm{m}$ ( $\times 10$ objective, $1 \times$ Optovar) overlying cartilage rings in tracheas stained for blood vessels (PECAM-1) and leukocytes (CD11b). Five regions were assessed in each trachea, beginning with the second cartilage ring caudal to the larynx and continuing consecutively toward the bronchi. Area density of CD11b-positive leukocytes (red pixels) was calculated with ImageJ software (http://rsh. info.nih.gov/ij), and images with fluorescence intensity greater than an empirically determined threshold value of 40 on a scale of 0 to 255 were included. ${ }^{23}$ The overall mean for each group ( $n=5$ mice) was calculated from the average value for all tracheal regions in each mouse.

\section{Bronchoalveolar Lavage and Leukocyte Counts}

Under anesthesia, the trachea was exposed surgically and a sterile 20-gauge catheter was inserted into the lumen for bronchoalveolar lavage (BAL), which consisted of infusion and withdrawal of three $0.8-\mathrm{ml}$ aliquots of PBS per mouse. Total leukocyte counts in BAL fluid were made with a hemacytometer, and counts of neutrophils, lymphocytes, and monocytes were made on Diff-Quickstained cells in BAL fluid spun down onto coverslips with a cytocentrifuge.

\section{Western Blots}

After vascular perfusion of PBS, tracheas were removed and homogenized in radioimmunoprecipitation assay buffer $(150 \mathrm{mmol} / \mathrm{L} \mathrm{NaCl}, 1 \% \mathrm{NP}-40,0.5 \%$ deoxycholic acid, $0.1 \%$ SDS, $50 \mathrm{mmol} / \mathrm{L}$ Tris $\mathrm{pH}$ 8.0) supplemented with Complete protease inhibitor cocktail (Roche, Applied Science, Indianapolis, IN). Protein content was measured by Bradford assay and equal amounts of pro-

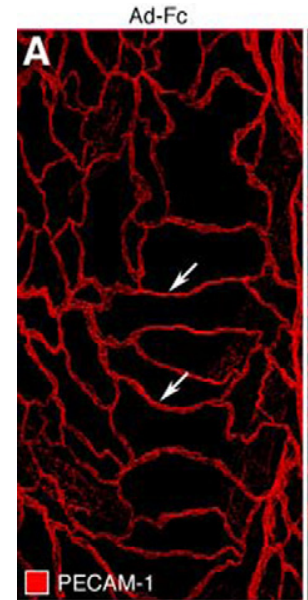

Ad-Fc
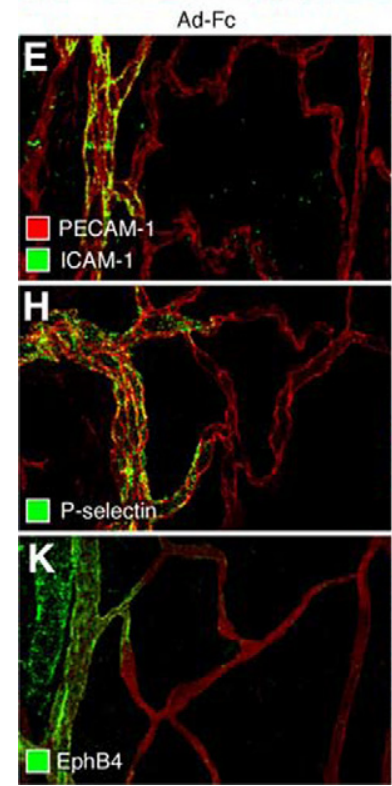

M. pulmonis

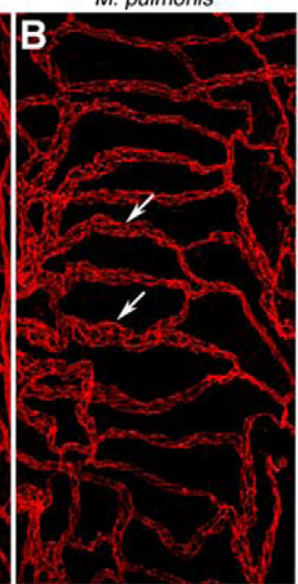

M. pulmonis
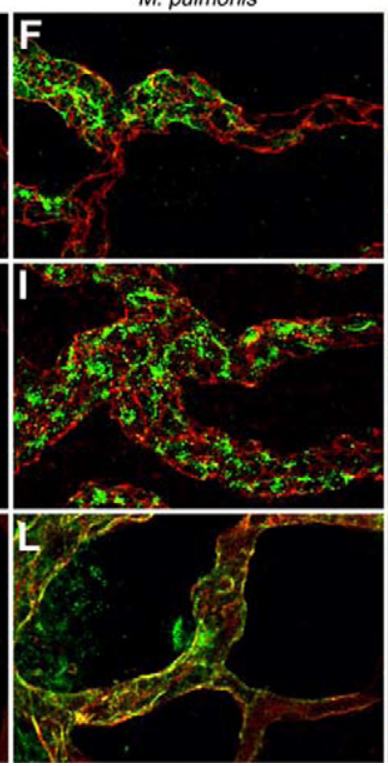

Ad-Ang1
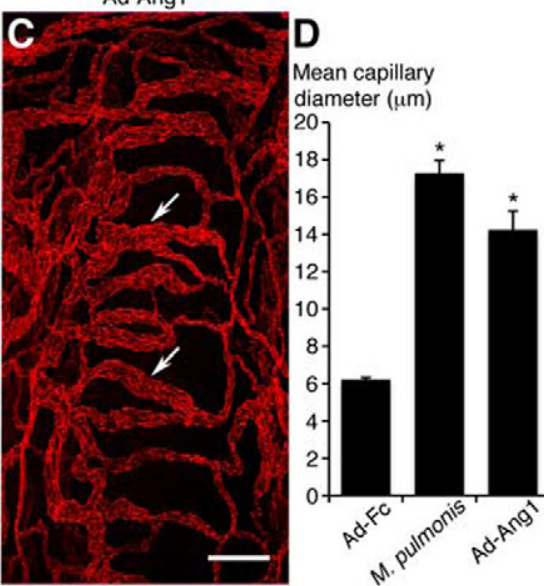

Ad-Ang1
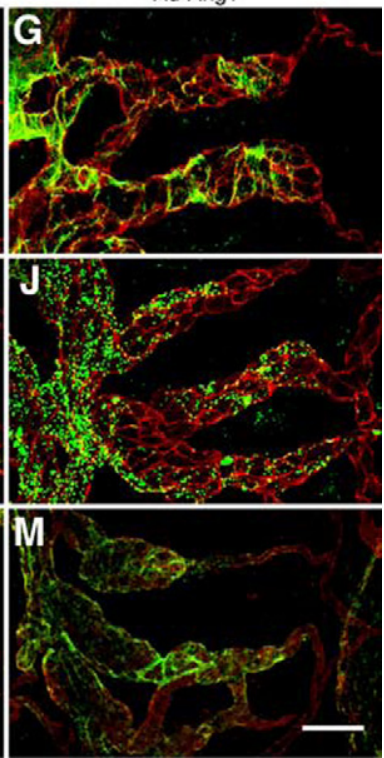

Figure 1. Remodeling of tracheal capillaries af ter $M$. pulmonis infection and Ad-Ang1. Immunofluorescence analysis of whole-mount mouse tracheas stained for PECAM-1 7 days after i.v. injection of $\mathrm{AdFC}$ (left panels), airway infection with $M$. pulmonis (middle panels), or i.v. injection of Ad-Ang1 (right panels). A: Normal trachea. Capillaries (arrows) traverse a cartilage ring. Arterioles and venules are located between cartilage rings. $\mathbf{B}$ and $\mathbf{C}$ : Enlarged capillaries 7 days after onset of $M$. pulmonis infection (B arrows) resemble remodeled capillaries after systemic overexpression of Ang1 (C, arrows). D: Bar graph showing capillary remodeling in tracheas of mice 7 days after the injection of AdFc, infection with $M$. pulmonis or i.v. injection of Ad-Ang1. Statistically different from AdFc $\left({ }^{*} P<0.05\right)$. E-M: Representative images showing staining of ICAM-1, P-selectin, and EphB4. In control mice (E, H, K), ICAM-1, P-selectin, and EphB4 were restricted to venules. After $M$. pulmonis (F, I, L) or Ad-Ang1 (G, J, M), expression of these markers extended into remodeled capillaries. Scale bars $=60 \mu \mathrm{m}(\mathbf{A}-\mathbf{C}) ; 30 \mu \mathrm{m}(\mathbf{D}-\mathbf{L})$. 
tein resolved by $12 \%$ SDS-polyacrylamide-gel electrophoresis under reducing conditions followed by blotting onto nitrocellulose membranes (Protran, Whatman, NJ). Membranes were incubated with antibodies against mouse Ang1 (ANG11-A, $\alpha$ Diagnostic), Ang2 (ANG21A, $\alpha$ Diagnostic), and $\beta$-actin (Abcam, Cambridge, UK) followed by horseradish peroxidase-conjugated secondary antibodies (Jackson ImmunoResearch). Immunoreactive bands were visualized via standard ECL (Supersignal, Thermo Fisher Scientific, Rockford, IL). For analysis of sTie2 expression in serum, $1 \mu$ l of serum from each mouse was diluted in loading buffer and subjected to SDS-PAGE. Blots were incubated with an antibody against Tie2 (clone 1E11DH, Chemicon/Millipore) and goat anti-rat secondary antibody (Jackson).

\section{Blood Collection and Quantitative PCR}

Total RNA was isolated using the "Mouse RiboPureBlood" isolation kit (Ambion) from $150 \mu$ l of blood. RNA yield and purity was determined by spectrophotometry.
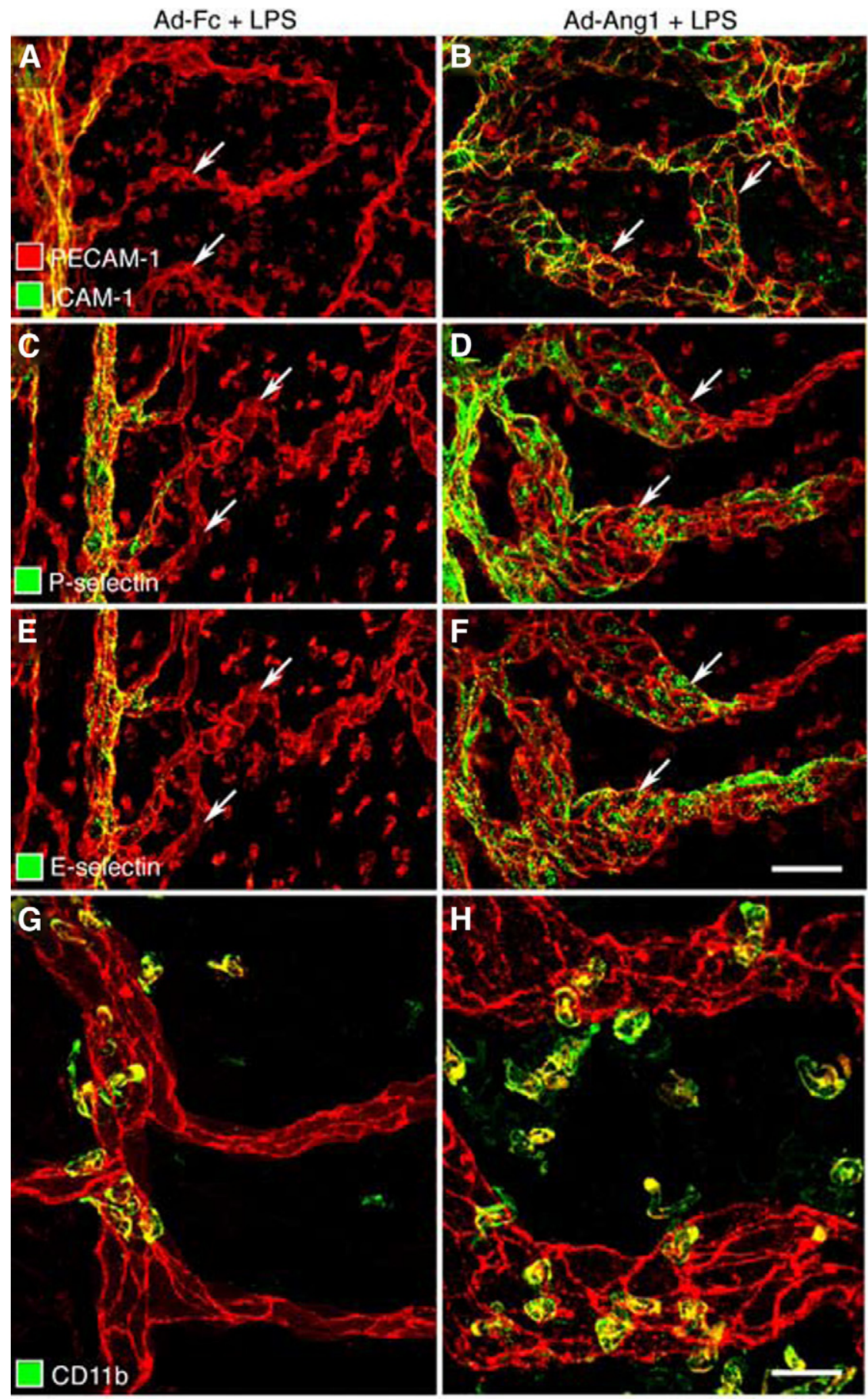

Figure 2. Endothelial cells of Ang1-remodelec capillaries respond to LPS similar to venous endothelial cells. A-F: Effect of LPS on the expression of ICAM-1, P-selectin, and E-selectin in trachea blood vessels. Mice received $\operatorname{Ad}-F_{C}(\mathbf{A}, \mathbf{C}, \mathbf{E})$ or Ad-Ang1 $(\mathbf{B}, \mathbf{D}, \mathbf{F})$, had intranasal inoculation of LPS 7 days later, and were studied 4 hours thereafter. ICAM-1, P-selectin, and E-selectin were not detected in capillaries of Ad-Fc mice (A, C, E arrows) but were detected in Ang1-remodeled capillaries (B, D, F, arrows). G-I: Comparison of the distribution of CD11b-positive leukocytes in the tracheal microvasculature of Ad-Fc-treated $(\mathbf{G})$ and Ad-Ang1-treated mice (H) 2 hours after LPS. I Bar graph showing number of intravascular leukocytes, stained by i.v. injection of lectin, in tracheal capillaries of Ad-Fc- and Ad-Ang1-treated mice under baseline conditions and 2 hours after LPS Number of leukocytes expressed per $100 \mu \mathrm{m}$ of tracheal capillary over cartilage ring. Statistically different from AdFC/AdAng1 - LPS ( $\left.{ }^{*} P<0.05\right)$; statistically different from AdFC + LPS (**: $P<0.05$ ) Scale bars $=30 \mu \mathrm{m}(\mathbf{A}-\mathbf{F}) ; 15 \mu \mathrm{m}(\mathbf{G}$ and $\mathbf{H})$.
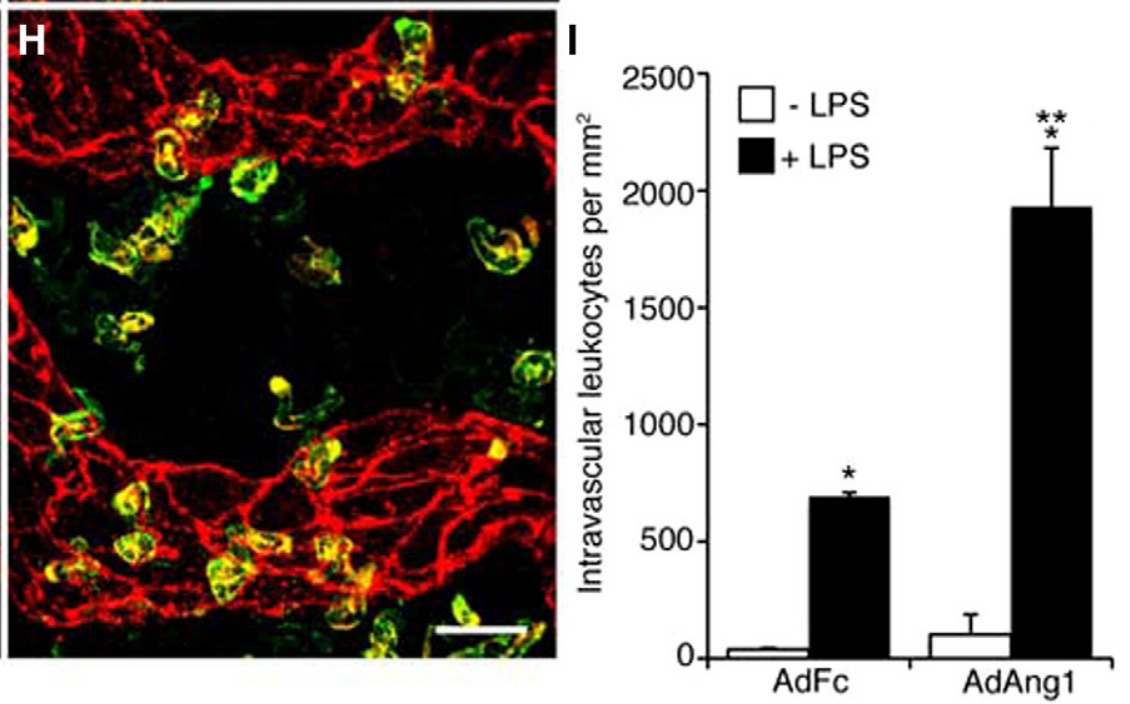
cDNA synthesis was performed with $1 \mu \mathrm{g}$ of total RNA using the cDNA synthesis kit (Roche). Quantitative PCR were performed using SYBR GreenER qPCR Supermix (Invitrogen) using a Bio-Rad MylQ detection system. The expression of each target gene was normalized to the expression of the control gene $\beta$-actin.

\section{Statistical Analysis}

Values are expressed as means \pm SEM with four to five mice per group. The significance of differences among groups was assessed by analysis of variance followed by the Dunn-Bonferroni posthoc test for multiple comparisons with differences considered significant where $P<0.05$

\section{Results}

\section{Ang1 Induces Remodeling of Capillaries into Venules}

The microvasculature of the tracheal mucosa of pathogen-free mice had a distinctive segmental organization. Uniformly narrow capillaries formed a ladder-like pattern over cartilaginous rings (Figure 1A). Venules were abundant in regions of the mucosa between cartilage rings, but few were located over the rings. Seven days after intranasal inoculation of $M$. pulmonis organisms, tracheal capillaries had become enlarged about twice normal diameter (Figure 1B). Postcapillary venules and collecting venules were similarly enlarged. Capillaries typical of the pathogen-free state were no longer present.

Seven days after systemic overexpression of Ang1 produced in pathogen-free mice by intravenous (i.v.) injection of the adenoviral vector Ad-Ang $1,{ }^{12}$ capillaries in the tracheal mucosa overlying cartilage rings were conspicuously enlarged (Figure $1 \mathrm{C}$ ). The size of remodeled capillaries increased toward the venous end, as found in the remodeled capillaries after M. pulmonis infection (Fig- ure 1C). Quantification of the remodeling showed that during a period of seven days, the mean capillary diameter had increased from $7 \mu \mathrm{m}$ in the Ad-Fc group to 14 and $16 \mu \mathrm{m}$ in the M. pulmonis and Ad-Ang1 groups, respectively (Figure 1D). Immunofluorescence staining for the venular markers ICAM-1, P-selectin, and EphB4 was detected in postcapillary venules and collecting venules of pathogen-free mice (Figure 1, E, H, and K). However, none of these was detected in capillaries. After M. pulmonis infection, both the remodeled capillaries and venules stained positive for all three molecules (Figure 1, F, I, and L). Endothelial cells of tracheal capillaries that underwent remodeling after Ad-Ang1 were also positive for ICAM-1, P-selectin, and EphB4 expression, typical of a venular phenotype (Figure 1, G, $J$, and $M$ ).

\section{Ang1-Remodeled Capillaries Function as Venules in Acute Airway Inflammation}

To determine whether the endothelial cells of Ang1-remodeled capillaries responded like venules to inflammatory stimuli, we induced acute airway inflammation by intranasal delivery of LPS. In mice challenged with LPS 7 days after injection of Ad-Fc or Ad-Ang1, the distribution of ICAM-1 and P-selectin expression in the tracheal vasculature was the same as without LPS (Figure 2, A-D). E-selectin, which was not detected in the tracheal microvasculature without LPS (See Supplemental Figure S1A at http://ajp.amjpathol.org), was detected in both groups after LPS (Figure 2, E and F). However, whereas the distribution of E-selectin after Ad-Fc was restricted to normal venules (Figure 2E), it was strong in both remodeled capillaries and venules after Ad-Ang1 (Figure 2F).

LPS inoculation was followed within 2 hours by recruitment of leukocytes into the tracheal microvasculature of mice treated with Ad-Fc or Ad-Ang1. However, the location and magnitude differed in the two groups. After $\mathrm{Ad}-\mathrm{Fc}$, most adherent leukocytes were located within or
A
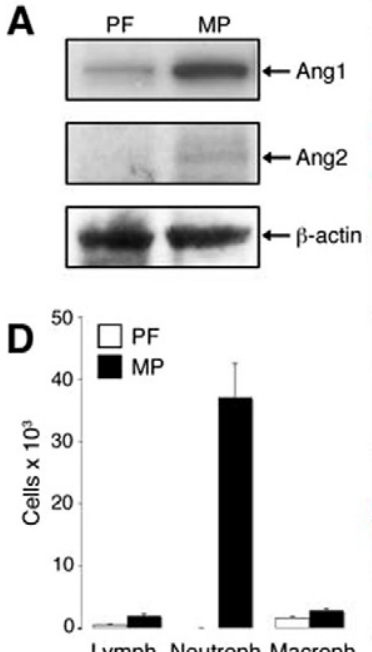
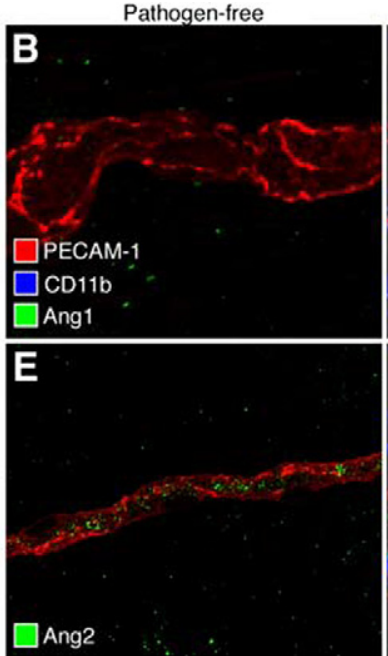

Lymph Neutroph Macroph
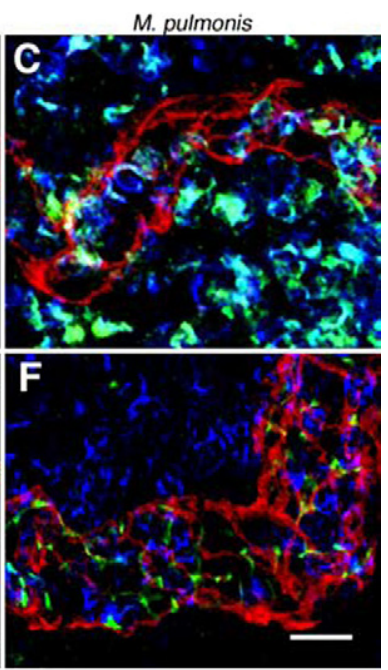

Figure 3. Ang1 and Ang2 are expressed in $M$. pulmonis-infected mouse airways. A: Immunoblot analyses of Ang1 and Ang2 protein (both migrating at around $75 \mathrm{kDa}$ ) in tracheas of pathogen-free (PF) and M. pulmonis-infected (MP) mice. $\beta$-actin was used as a loading control. $\mathbf{B}$ and $\mathbf{C}, \mathbf{E}$ and $\mathbf{F}$ : Immunofluorescence analysis of Ang1 and Ang2 expression in whole-mount tracheas of pathogenfree $(\mathbf{B}$ and $\mathbf{E})$ and $M$. pulmonis-infected $(\mathbf{C}$ and $\mathbf{F})$ mice. Blood vessels were stained for PECAM-1 and myeloid cells for CD11b. (D) Bar graph showing average lymphocyte, neutrophil, and macrophage counts in the bronchoalveolar lavage fluid of $\mathrm{PF}$ and MP mice. Mean values are from three independent experiments. Scale bar $=10 \mu \mathrm{m}(\mathbf{B}$ and $\mathbf{C}$ $\mathbf{E}$ and $\mathbf{F}$ ) 
near venules (Figure 2G), but after Ad-Ang1, leukocytes were abundant within and around remodeled capillaries and venules (Figure 2, $\mathrm{H}$ and I). These experiments showed that Ad-Ang1 induced remodeling of airway capillaries into blood vessels having the structural and functional characteristics of venules and thus resembled those found after M. pulmonis infection.

\section{Different Sources of Ang1 and Ang2 in M. pulmonis-Infected Mouse Airways}

Ang1 protein levels were increased in tracheas of mice infected with M. pulmonis infection compared with pathogen-free mice (Figure 3A). A slight increase in Ang2 levels was also detected (Figure 3A). Immunofluorescence analysis of whole-mount tracheas showed no evidence of Ang1 staining in tracheas of pathogen-free mice (Figure 3B) but widespread Ang1 staining in leukocytes in the tracheal mucosa of mice infected with $M$. pulmonis for 7 days (Figure 3C). Ang 1 was associated with CD11bpositive leukocytes that had multilobed nuclei characteristic of neutrophils (Figure $3 \mathrm{C}$ ). Neutrophils were the dominant cell type in BAL fluid from mice infected with $M$. pulmonis for 7 days (Figure 3D). Ang2 staining had a granular pattern in endothelial cells of tracheal venules and capillaries in pathogen-free mice (Figure 3E). After infection, Ang2 expression was intensified in venules and remodeled capillaries and the localization changed from a granular to a more distinct pattern, which partly overlapped with PECAM-1 and was most intense in regions where neutrophils adhered to or migrated through the endothelium (Figure 3F).

Immunofluorescence analysis of cells in the peripheral blood revealed Ang1 staining in a subset of leukocytes, both in pathogen-free mice (data not shown) and in infected mice (See Supplemental Figures S2, A, B, and C at http://ajp.amjpathol.org). Most Ang1-positive cells were CD11b- and CD45-positive neutrophils with multilobed nuclei (Supplemental Figure S2A, see http://ajp.amjpathol. org). Some Ang1 staining was also detected in monocytes (Supplemental Figure S2C, see http://ajp.amjpathol. org), whereas CD11b negative lymphocytes seemed to be negative (Supplemental Figure S2B, see http://ajp. amjpathol.org). Ang2 staining was most evident in lymphocytes (Supplemental Figure S2B, see http://ajp.amjpathol. org) and monocytes (Supplemental Figure S2C, see http:// ajp.amjpathol.org), whereas neutrophils seemed less positive (Supplemental Figure S2A, see http://ajp.amjpathol.org). Ang1 mRNA (Supplemental Figure S3, http://ajp.amjpathol. org), but not Ang2 mRNA (data not shown), was detected by qRT-PCR in peripheral blood leukocytes and was not significantly different in pathogen-free versus $M$. pulmonisinfected mice.
A
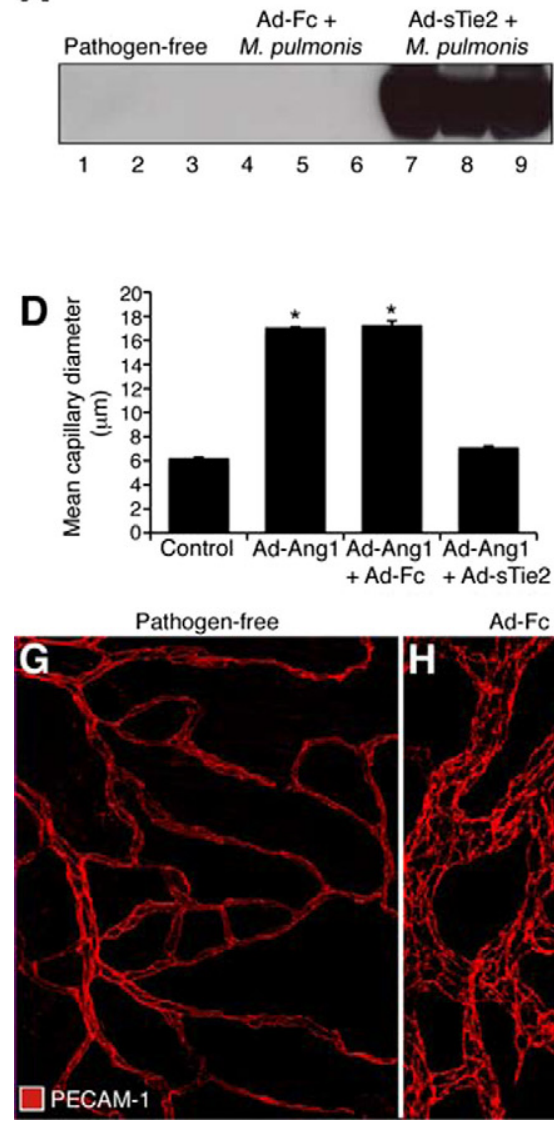
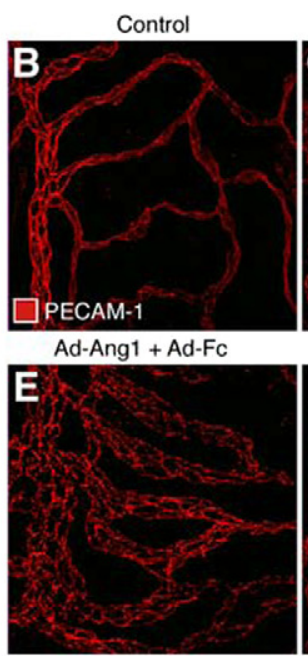

Ad-Fc $+M$. pulmonis

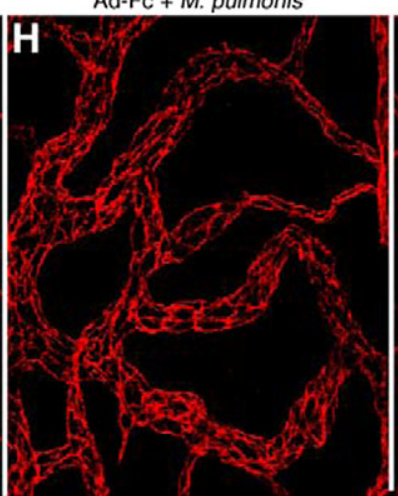

Ad-Ang1

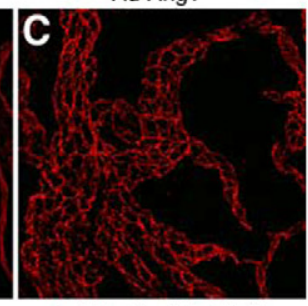

Ad-Ang1 + Ad-sTie2

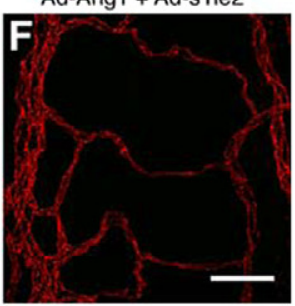

Ad-sTie2 + M. pulmonis

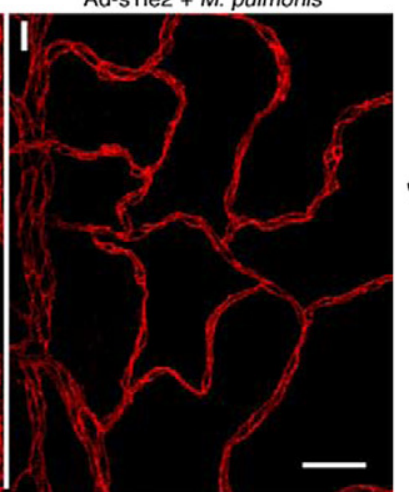

Figure 4. Soluble Tie2 blocks capillary remodeling in the mouse trachea after AdAng1 and M. pulmonis infection. A: Western blot analysis of sTie 2 protein in serum from pathogen-free mice (lanes 1-3) and $M$. pulmonis-infected mice injected with Ad-Fc (lanes 4-6) or Ad-sTie2 (lanes 7-9). B and C $\mathbf{E}$ and $\mathbf{F}$ : Representative images of tracheal whole mounts stained for PECAM-1 to compare tracheal capillaries of pathogen-free mice (B) with remodeled capillaries in mice injected with Ad-Ang1 alone (C) or in combination with Ad-Fc (E) or Ad-sTie2 (F). D Graph showing capillary remodeling, as reflected by vessel diameter $(\mathrm{mm})$, in tracheas of pathogen-free mice and $M$. pulmonis-infected mice injected with Ad-Fc or Ad-sTie2. *Statistically different from control $(P<$ 0.05). G-I: Tracheal whole mounts stained for PECAM-1 comparing tracheal capillaries of pathogen-free mice $(\mathbf{G})$ with remodeled capillaries in $M$. pulmonis-infected mice injected with Ad-Fc (H) or Ad-sTie2 (I). J: Graph showing capillary remodeling in tracheas of pathogen-free mice and mice infected with $M$. pulmonis and injected with Ad-Fc or Ad-sTie2. Statistically different from pathogen-free $\left({ }^{*} P<0.05\right)$. Scale bars $=50 \mu \mathrm{m}$ (B and $\mathbf{C}, \mathbf{E}$ and $\mathbf{F}) ; 30 \mu \mathrm{m}(\mathbf{G}$ through $\mathbf{I})$.

\section{J}

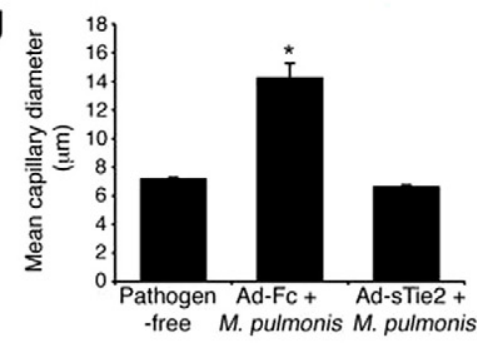


The Ang/Tie2 Pathway Drives Remodeling of Capillaries into Venules in M. pulmonis-Induced Airway Inflammation

The data from the overexpression studies showed that Ang1 could induce remodeling of tracheal capillaries similar to what happens after airway infection with $M$. pulmonis and that both Ang1 and Ang2 were expressed in $M$. pulmonis-infected mouse airways. To determine whether angiopoietin/Tie2 signaling drives vascular remodeling after M. pulmonis infection, we used an adenoviral vector encoding soluble Tie2 ectodomains (Ad-sTie2) that binds and sequesters Tie2 ligands and thereby blocks their action on Tie2 receptors on endothelial cells of airway blood vessels.

Purified sTie2 from adenovirus supernatants neutralized Ang1-stimulated Akt phosphorylation in cultured human umbilical vein endothelial cells. ${ }^{26}$ Intravenous injection of Ad-sTie2 in M. pulmonis-infected mice resulted in production of sTie2 in the liver, as shown by strong sTie2 staining in hepatocytes (Supplemental Figure S1B, see http://ajp.amjpathol.org), and secretion of detectable amount of protein in serum 7 days after i.v. injection
(Figure 4A). No sTie2 was detected in mice that received no adenovirus or Ad-Fc (Figure 4A). Immunofluorescence staining for mouse $\mathrm{Fc}_{\mathrm{C}}$ was detected in liver after both Ad-Fc and Ad-sTie2 (Supplemental Figure S1B, see http://ajp.amipathol.org). Co-injection of Ad-sTie2, but not $\mathrm{Ad}-\mathrm{Fc}$, in pathogen-free mice inhibited the remodeling induced in tracheal capillaries by Ad-Ang1 (Figure 4, B, C, E, and F). Quantification of changes in capillary diameter showed that capillary remodeling after Ad-Ang1 was almost completely blocked by Ad-sTie2 (Figure 4D), showing that the sTie2 could block Ang/Tie2 signaling also in vivo. To determine whether Ad-sTie2 could inhibit capillary remodeling in the mouse airways after $M$. pulmonis infection, we injected Ad-sTie2 or Ad-Fc one day before inoculation of $M$. pulmonis and examined the effects on tracheal capillaries 7 days later. Whereas remodeling of tracheal capillaries was conspicuous in infected mice that received Ad-Fc (Figure 4, G and $\mathrm{H}$ ), remodeling was completely blocked in infected mice treated with Ad-sTie2 (Figure 4, I and J).

P-selectin immunoreactivity was present in remodeled capillaries of $M$. pulmonis-infected mice treated with Ad-Fc (Figure 5, A and B) but was restricted to venules in
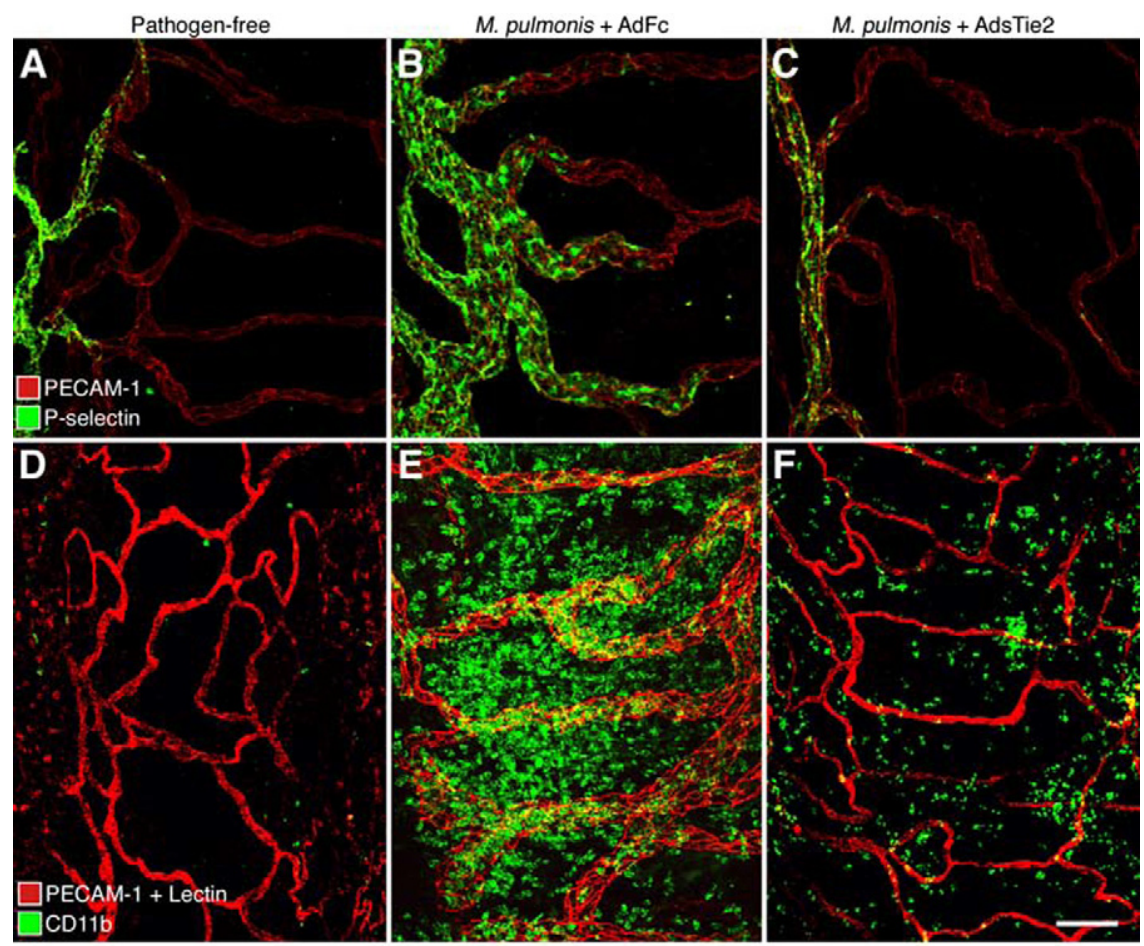

G

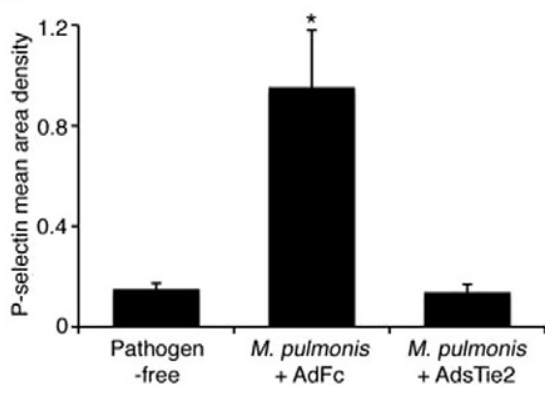

H

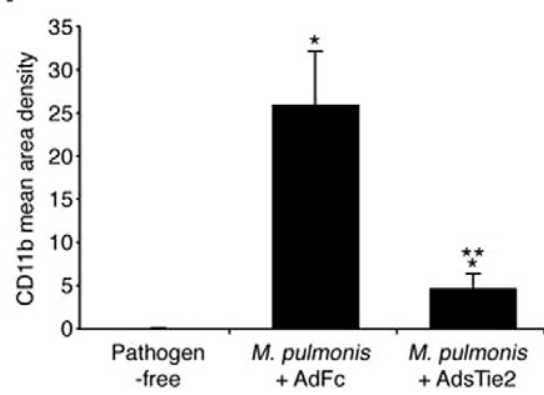

Figure 5. Soluble Tie2 inhibits venous transformation of capillaries and leukocyte infiltration in the mouse trachea after $M$. pulmonis infection. A-F: Representative images of tracheal whole mounts stained for PECAM-1 and P-selectin or CD11b to compare P-selectin expression in capillaries (A-C) and infiltration of CD11b-positive leukocytes (D-F) in tracheas of pathogen-free mice (A and $\mathbf{D}$ ) and mice infected with $M$. pulmonis and injected with $\mathrm{Ad}-\mathrm{Fc}$ (B and $\mathbf{E}$ ) or Ad-sTie2 (C and F). Few CD11b-positive cells were detected in tracheas of pathogen-free mice (D). CD11b-positive cells were abundant in tracheas of $M$. pulmonis-infected mice injected with Ad-Fc (E) but less abundant in tracheas of M. pulmonis-infected mice injected with AdsTie2 (F). G: Bar graph showing area density measurement of P-selectin fluorescence in tracheal capillaries of pathogen-free mice and mice infected with $M$. pulmonis and injected with Ad-FC or Ad-sTie2. *Statistically different from pathogen-free $(P<0.05)$. H: Bar graph showing area density measurement of CD11b-positive leukocytes in tracheas of pathogen-free mice and mice infected with $M$. pulmonis and injected with Ad-Fc or Ad-sTie2. Statistically different from control $\left({ }^{*} P<0.05\right)$ statistically different from $M$. pulmonis $+\operatorname{AdFc}(* * P<0.05)$. Scale bars $=30 \mu \mathrm{m}(\mathbf{A}-\mathbf{F})$. 
mice that received Ad-sTie2 (Figure 5C). Quantification of these results showed that the increase in P-selectin area density over capillaries was completely inhibited by AdsTie2 (Figure 5G). Compared with pathogen-free mice (Figure 5D), leukocyte influx was abundant in the mouse trachea of $M$. pulmonis-infected mice treated with Ad-Fc (Figure 5E), but less in mice given Ad-sTie2 (Figure 5F). Quantification of these results showed that Ad-sTie2 caused an $80 \%$ reduction of leukocyte accumulation in tracheas of $M$. pulmonis-infected mice (Figure $5 \mathrm{H}$ ). Altogether, these results are consistent with an essential role of Ang/Tie2 signaling in capillary remodeling into venules in inflammation associated with M. pulmonis infection.

\section{Discussion}

The aim of this study was to determine the role of the Ang/Tie2 pathway in the vascular remodeling that accompanies airway inflammation after M. pulmonis infection. We found that overexpression of Ang1 induced remodeling of capillaries into venular-like vessels similar to what is seen after M. pulmonis infection. Previous studies have shown that vascular remodeling induced by $M$. pulmonis or Ang1 is not VEGF-dependent. ${ }^{3,23}$ Here, we found that the Ang/Tie2 pathway plays an essential role as a driving force for vascular remodeling after M. pulmonis and that inhibition of Ang/Tie2 signaling, using soluble Tie2, efficiently blocked both remodeling and leukocyte influx in infected mouse airways.

The remodeled capillaries expressed P-selectin and ICAM-1, inflammatory markers of venous endothelial cells, and EphB4, a lineage marker of venous endothelial cells, and supported leukocyte adhesion under inflammatory conditions indicating that they were transformed into venules after M. pulmonis infection or Ad-Ang1. Eselectin was induced in remodeled capillaries during inflammatory conditions suggesting that endothelial cells of remodeled capillaries acquired a venous endothelial cell program, which made them able to respond to inflammatory stimuli similar to venous endothelial cells. The results agree with published data showing that both Ang1 and Ang2 share the capacity to stimulate neutrophil adhesion to endothelial cells by inducing P-selectin translocation, ${ }^{29,30}$ but somewhat contrast to reports showing that overexpressed Ang1, or COMP-Ang1, decreases VEGF-induced expression of inflammatory cell adhesion molecules in cultured endothelial cells. ${ }^{31}$ Different experimental conditions like in vitro versus in vivo, short-term versus long-term exposure, and the usage of different inflammatory stimuli may explain the variability.

Venules are the primary site for plasma leakage and leukocyte trafficking in inflammation because of the fact that venous endothelial cells express receptors for inflammatory mediators that trigger endothelial gap formation $^{32}$ and cell adhesion molecules involved in leukocyte adhesion and transmigration. ${ }^{33,34}$ Based on our results and published data showing that activating mutations in Tie2 causes inherited venous malformations ${ }^{35}$ and that Ang1 may be specifically expressed in mesenchymal cells surrounding veins during vascular development, ${ }^{36}$ we speculate that Ang1 may play a role in promoting venous identity. However, fate mapping techniques are necessary to examine to what extent venular transformation of capillaries represent a true phenotypic shift of capillary endothelial cells or an expansion of venular cells into the capillary bed.

Similar to us, others have found increased levels of Ang1 and Ang2 in inflammatory conditions accompanied by capillary remodeling, such as asthma, psoriasis, and IBD. 37-40 Interestingly, Ang1 and Ang2 were produced by different cellular sources-neutrophils and endothelial cells, respectively. We find this interesting because it may suggest that neutrophil Ang1 could play a role in regulating the vascular function/phenotype in various conditions of inflammation involving neutrophil influx. Similarly, it was recently reported that Ang1, but not Ang2, is expressed in human neutrophils where it is stored in the cytosolic fraction and released by phorbol myristate acetate. ${ }^{41}$ Blockade of neutrophil infiltration results in reduced vascular remodeling after $M$. pulmonis, ${ }^{28}$ supporting a role for neutrophil Ang1. Others have also reported that leukocytes represent a source of Ang 1 in pathological conditions of vascular remodeling. Ang1 from neutrophils promote choroidal neovascularization, ${ }^{42}$
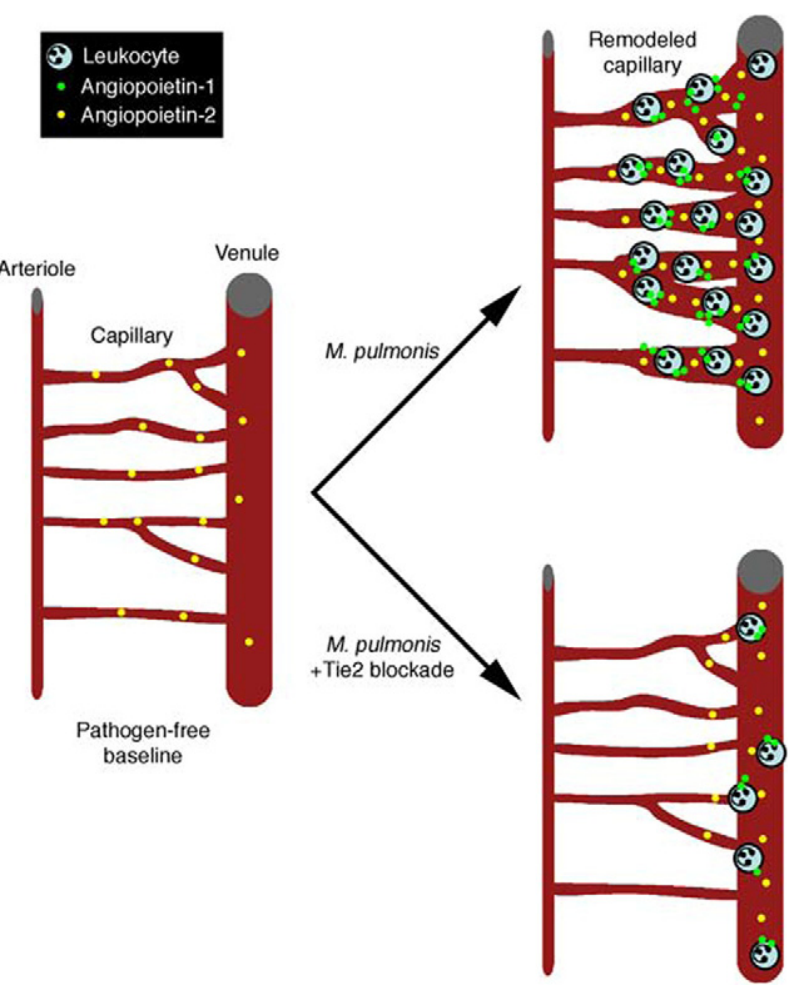

Figure 6. The Ang/Tie2 pathway promotes capillary remodeling and leukocyte infiltration in $M$. pulmonis-induced airway inflammation. During the first week of $M$. pulmonis infection tracheal capillaries are remodeled into vessels with properties of venules. The result is a net increase in the total vascular surface area that participates in the inflammatory response, which leads to more efficient leukocyte infiltration into the airways. Systemic administration of sTie2 blocks remodeling and reduces leukocyte infiltration showing a critical role for the Ang/Tie2 pathway in driving capillary remodeling in $M$. pulmonis-infected mouse airways. In support of this, both Ang1 and Ang2 accumulate in $M$. pulmonis-infected mouse tracheas but are produced from different cellular sources-Ang1 from invading neutrophils and Ang2 from endothelial cells-suggesting that they may cooperate to regulate vascular remodeling and leukocyte infiltration in inflammation. 
and mast cell-derived Ang1 drives angiogenesis in plasma cell tumors. ${ }^{43}$ Soluble Tie2 blocked, similar to our studies, these effects. The altered expression pattern of Ang2 in endothelial cells of remodeled capillaries suggested redistribution from Weibel-Palade bodies to regions of neutrophil adhesion. This could reflect Ang2 interaction with Tie2 receptors on endothelial cells and/or leukocytes, in line with a role of Ang2 in regulating leukocyte trafficking under inflammatory conditions. ${ }^{44}$ Further studies using specific inhibitors of Ang1 and Ang2 are needed to define the relative roles of Ang1 and Ang2 for vascular remodeling and leukocyte infiltration under inflammatory conditions.

In summary, our results demonstrate that the Ang/Tie2 pathway is an essential mediator of vascular remodeling and leukocyte infiltration in the mouse airways after $M$. pulmonis (Figure 6). Venous transformation of capillaries results in a net increase of the total vascular surface area, which participates in the inflammatory response, thereby promoting more efficient leukocyte infiltration. We hypothesize that this may be a mechanism used by tissues to adapt to sustained/chronic inflammatory conditions by expanding the venous segment of the microvasculature through mobilization of capillaries. This mechanism could contribute to the transition from acute to chronic inflammation where excess amounts of leukocytes promote tissue damage and fibrosis by releasing various cytokines, growth factors, and proteases. ${ }^{45,46}$ Based on our results, we propose that the Ang/Tie2 pathway is a major driving force for this type of vascular remodeling and a potential therapeutic target for blocking leukocyte infiltration and subsequent tissue remodeling in chronic inflammation.

\section{Acknowledgments}

We thank Steven Rosen (Department of Anatomy, UCSF) for valuable discussions and DongJi Zhang (UCSF) for production of the M. pulmonis stock.

\section{References}

1. Ferrara N, Mass RD, Campa C, Kim R: Targeting VEGF-A to treat cancer and age-related macular degeneration. Annu Rev Med 2007, 58:491-504

2. Folkman J: Role of angiogenesis in tumor growth and metastasis. Semin Oncol 2002, 29:15-18

3. McDonald DM: Angiogenesis and vascular remodeling in inflammation and cancer. Edited by Figg WD, Folkman J. New York, Springer, 2008, p. 17-35

4. Costa C, Incio J, Soares R: Angiogenesis and chronic inflammation: cause or consequence? Angiogenesis 2007, 10:149-166

5. McDonald DM: Angiogenesis and remodeling of airway vasculature in chronic inflammation. Am J Respir Crit Care Med 2001, 164:S39-S45

6. Li X, Wilson JW: Increased vascularity of the bronchial mucosa in mild asthma. Am J Respir Crit Care Med 1997, 156:229-233

7. Braverman IM, Yen A: Ultrastructure of the capillary loops in the dermal papillae of psoriasis. J Invest Dermatol 1977, 68:53-60

8. Danese S, Sans M, de la Motte C, Graziani C, West G, Phillips MH, Pola R, Rutella S, Willis J, Gasbarrini A, Fiocchi C: Angiogenesis as a novel component of inflammatory bowel disease pathogenesis. Gastroenterology 2006, 130:2060-2073

9. Thurston G, Rudge JS, loffe E, Papadopoulos N, Daly C, Vuthoori S,
Daly T, Wiegand SJ, Yancopoulos GD: The anti-inflammatory actions of angiopoietin-1, EXS 2005, 233-245

10. Walshe TE, Dole VS, Maharaj AS, Patten IS, Wagner DD, D'Amore PA: Inhibition of VEGF or TGF-\{beta\} signaling activates endothelium and increases leukocyte rolling. Arterioscler Thromb Vasc Biol 2009, 29:1185-1192

11. Suri C, McClain J, Thurston G, McDonald DM, Zhou H, Oldmixon EH, Sato TN, Yancopoulos GD: Increased vascularization in mice overexpressing angiopoietin-1. Science 1998, 282:468-471

12. Thurston G, Wang Q, Baffert F, Rudge J, Papadopoulos N, JeanGuillaume D, Wiegand S, Yancopoulos GD, McDonald DM: Angiopoietin 1 causes vessel enlargement, without angiogenic sprouting, during a critical developmental period. Development 2005, 132:3317-3326

13. Yancopoulos GD, Davis S, Gale NW, Rudge JS, Wiegand SJ, Holash $\mathrm{J}$ : Vascular-specific growth factors and blood vessel formation. Nature 2000, 407:242-248

14. Fiedler U, Augustin HG: Angiopoietins: a link between angiogenesis and inflammation. Trends Immunol 2006, 27:552-558

15. Sato TN, Tozawa Y, Deutsch U, Wolburg-Buchholz K, Fujiwara $Y$, Gendron-Maguire M, Gridley T, Wolburg H, Risau W, Qin Y: Distinct roles of the receptor tyrosine kinases Tie-1 and Tie-2 in blood vessel formation. Nature 1995, 376:70-74

16. Suri C, Jones PF, Patan S, Bartunkova S, Maisonpierre PC, Davis S, Sato TN, Yancopoulos GD: Requisite role of angiopoietin-1, a ligand for the TIE2 receptor, during embryonic angiogenesis. Cell 1996, $87: 1171-1180$

17. Gale NW, Thurston G, Hackett SF, Renard R, Wang Q, McClain J, Martin C, Witte C, Witte MH, Jackson D, Suri C, Campochiaro PA, Wiegand SJ, Yancopoulos GD: Angiopoietin-2 is required for postnatal angiogenesis and lymphatic patterning, and only the latter role is rescued by Angiopoietin-1. Dev Cell 2002, 3:411-423

18. Saharinen $P$, Eklund L, Miettinen J, Wirkkala R, Anisimov A, Winderlich M, Nottebaum A, Vestweber D, Deutsch U, Koh GY, Olsen BR, Alitalo K: Angiopoietins assemble distinct Tie2 signalling complexes in endothelial cell-cell and cell-matrix contacts. Nat Cell Biol 2008, 10:527-537

19. Fukuhara S, Sako K, Minami T, Noda K, Kim HZ, Kodama T, Shibuya M, Takakura N, Koh GY, Mochizuki N: Differential function of Tie2 at cell-cell contacts and cell-substratum contacts regulated by angiopoietin-1. Nat Cell Biol 2008, 10:513-526

20. Maisonpierre PC, Suri C, Jones PF, Bartunkova S, Wiegand SJ, Radziejewski C, Compton D, McClain J, Aldrich TH, Papadopoulos N, Daly TJ, Davis S, Sato TN, Yancopoulos GD: Angiopoietin-2, a natural antagonist for Tie2 that disrupts in vivo angiogenesis. Science 1997, 277:55-60

21. Bogdanovic E, Nguyen VP, Dumont DJ: Activation of Tie2 by angiopoietin-1 and angiopoietin-2 results in their release and receptor internalization. J Cell Sci 2006, 119:3551-3560

22. Daly C, Pasnikowski E, Burova E, Wong V, Aldrich TH, Griffiths J, loffe E, Daly TJ, Fandl JP, Papadopoulos N, McDonald DM, Thurston G, Yancopoulos GD, Rudge JS: Angiopoietin-2 functions as an autocrine protective factor in stressed endothelial cells. Proc Natl Acad Sci USA 2006, 103:15491-15496

23. Baffert F, Thurston G, Rochon-Duck M, Le T, Brekken R, McDonald DM: Age-related changes in vascular endothelial growth factor dependency and angiopoietin-1-induced plasticity of adult blood vessels. Circ Res 2004, 94:984-992

24. Thurston G, Suri C, Smith K, McClain J, Sato TN, Yancopoulos GD, McDonald DM: Leakage-resistant blood vessels in mice transgenically overexpressing angiopoietin-1. Science 1999, 286:2511-2514

25. Thurston G, Rudge JS, loffe E, Zhou H, Ross L, Croll SD, Glazer N Holash J, McDonald DM, Yancopoulos GD: Angiopoietin-1 protects the adult vasculature against plasma leakage. Nat Med 2000, 6:460-463

26. Kuhnert F, Tam BY, Sennino B, Gray JT, Yuan J, Jocson A, Nayak NR, Mulligan RC, McDonald DM, Kuo CJ: Soluble receptor-mediated selective inhibition of VEGFR and PDGFRbeta signaling during physiologic and tumor angiogenesis. Proc Natl Acad Sci USA 2008, 105:10185-10190

27. Baffert F, Le T, Thurston G, McDonald DM: Angiopoietin-1 decreases plasma leakage by reducing number and size of endothelial gaps in venules. Am J Physiol Heart Circ Physiol 2006, 290:H107-H118

28. Aurora AB, Baluk P, Zhang D, Sidhu SS, Dolganov GM, Basbaum C, McDonald DM, Killeen N: Immune complex-dependent remodeling of 
the airway vasculature in response to a chronic bacterial infection. J Immunol 2005, 175:6319-6326

29. Lemieux C, Maliba R, Favier J, Theoret JF, Merhi Y, Sirois MG: Angiopoietins can directly activate endothelial cells and neutrophils to promote proinflammatory responses. Blood 2005, 105:1523-1530

30. Maliba R, Brkovic A, Neagoe P-É, Villeneuve LR, Sirois MG: Angiopoietin-mediated endothelial P-selectin translocation: cell signaling mechanisms. J Leukoc Biol 2008, 83:352-360

31. Kim KE, Cho CH, Kim HZ, Baluk P, McDonald DM, Koh GY: In vivo actions of angiopoietins on quiescent and remodeling blood and lymphatic vessels in mouse airways and skin. Arterioscler Thromb Vasc Biol 2007, 27:564-570

32. Thurston G, Baluk P, McDonald DM: Determinants of endothelial cell phenotype in venules. Microcirculation 2000, 7:67-80

33. Majno G, Palade GE, Schoefl GI: Studies on inflammation. II The site of action of histamine and serotonin along the vascular tree: a topographic study. J Biophys Biochem Cytol 1961, 11:607-626

34. Marchesi VT, Florey HW: Electron micrographic observations on the emigration of leucocytes. Q J Exp Physiol Cogn Med Sci 1960, 45:343-348

35. Vikkula M, Boon LM, Carraway KL 3rd, Calvert JT, Diamonti AJ, Goumnerov B, Pasyk KA, Marchuk DA, Warman ML, Cantley LC, Mulliken JB, Olsen BR: Vascular dysmorphogenesis caused by an activating mutation in the receptor tyrosine kinase TIE2. Cell 1996, 87:1181-1190

36. Moyon D, Pardanaud L, Yuan L, Breant C, Eichmann A: Selective expression of angiopoietin 1 and 2 in mesenchymal cells surrounding veins and arteries of the avian embryo. Mech Dev 2001, 106:133-136

37. Feltis BN, Wignarajah D, Zheng L, Ward C, Reid D, Harding R, Walters $\mathrm{EH}$ : Increased vascular endothelial growth factor and receptors: relationship to angiogenesis in asthma. Am J Respir Crit Care Med 2006, 173:1201-1207

38. Kanazawa H, Nomura S, Asai K: Roles of angiopoietin-1 and angiopoietin-2 on airway microvascular permeability in asthmatic patients. Chest 2007, 131:1035-1041

39. Koutroubakis IE, Tsiolakidou G, Karmiris K, Kouroumalis EA: Role of angiogenesis in inflammatory bowel disease. Inflamm Bowel Dis 2006, 12:515-523

40. Kuroda K, Sapadin A, Shoji T, Fleischmajer R, Lebwohl M: Altered expression of angiopoietins and Tie2 endothelium receptor in psoriasis. J Invest Dermatol 2001, 116:713-720

41. Neagoe PE, Brkovic A, Hajjar F, Sirois MG: Expression and release of angiopoietin-1 from human neutrophils: Intracellular mechanisms. Growth Factors 2009, 27:335-344

42. Zhou J, Pham L, Zhang N, He S, Gamulescu MA, Spee C, Ryan SJ, Hinton DR: Neutrophils promote experimental choroidal neovascularization. Mol Vis 2005, 11:414-424

43. Nakayama T, Yao L, Tosato G: Mast cell-derived angiopoietin-1 plays a critical role in the growth of plasma cell tumors. J Clin Invest 2004, 114:1317-1325

44. Fiedler U, Reiss Y, Scharpfenecker M, Grunow V, Koidl S, Thurston G, Gale NW, Witzenrath M, Rosseau S, Suttorp N, Sobke A, Herrmann M, Preissner KT, Vajkoczy P, Augustin HG: Angiopoietin-2 sensitizes endothelial cells to TNF-alpha and has a crucial role in the induction of inflammation. Nat Med 2006, 12:235-239

45. Eyles JL, Roberts AW, Metcalf D, Wicks IP: Granulocyte colonystimulating factor and neutrophils-forgotten mediators of inflammatory disease. Nat Clin Pract Rheumatol 2006, 2:500-510

46. Geng JG: Directional migration of leukocytes: their pathological roles in inflammation and strategies for development of anti-inflammatory therapies. Cell Res 2001, 11:85-88 